\title{
Design, Synthesis, Antimicrobial and Anticancer Activity of some Novel Benzoxazole-Isatin Conjugates
}

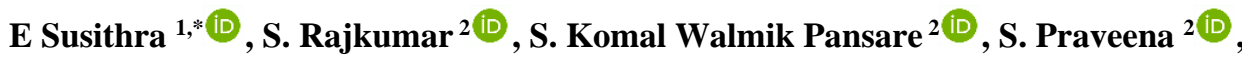 \\ PV. Parvati Sai Arun ${ }^{3(\mathbb{D})}$, Rajasekhar Chekkara ${ }^{4}$, , Gangarapu Kiran ${ }^{5(\mathbb{C}}$
}

1 Department of Pharmacognosy, School of Pharmaceutical Sciences, Vels Institute of Science, Technology and Advanced Studies (VISTAS), Pallavaram, Chennai - 600117, Tamilnadu, India

2 School of Pharmaceutical Sciences, Vels Institute of Science, Technology and Advanced Studies (VISTAS), Pallavaram, Chennai - 600117, Tamilnadu, India

3 Centre for Skill Development, Central Tribal University of Andhra Pradesh, Vizianagaram, Andhra Pradesh, India

4 Department of Chemistry, Sathyabama Institute of Science and Technology (Deemed to be University), Jeppiaar Nagar, Rajiv Gandhi Salai, Chennai - 600 119, Tamilnadu, India

5 School of Pharmacy, Anurag University, Venkatapur, Ghatkaser, Hyderabad, Telangana-500 088, India, gangakiran1905@gmail.com (G.K.);

* Correspondence: dresusithra21@gmail.com;

Scopus Author ID 56090040800

Received: 15.04.2021; Revised: 20.05.2021; Accepted: 28.05.2021; Published: 18.06.2021

\begin{abstract}
A series of novel benzoxazole-isatin conjugates were synthesized by treating 2-amino benzoxazole with 5 and 7 substituted isatin derivatives and were screened for in vitro antimicrobial and cytotoxic activities. The results showed that all the synthesized compounds shown mild to potent antibacterial activity. The MIC values were found between 10 and $100 \mu \mathrm{g} / \mathrm{ml}$ against tested bacterial and fungal organisms. Among all the compounds, $3 \mathrm{~d} \& 3 \mathrm{c}$ showed good antimicrobial. In vitro cytotoxic activities were evaluated by MTT assay of all the test compounds against the different human cancer cell lines. The compounds having substitution with electron-withdrawing groups (halides) at the 5th position on the isatin ring showed the most significant biological activity than substituted at the $7^{\text {th }}$ position. The molecular docking interactions have shown good binding interactions with the protein targets glucosamine-6-phosphate synthase (GlcN-6-P synthase) and telomerase.
\end{abstract}

Keywords: isatin; benzoxazole; indole; antimicrobial; anti-cancer; MTT.

(C) 2021 by the authors. This article is an open-access article distributed under the terms and conditions of the Creative Commons Attribution (CC BY) license (https://creativecommons.org/licenses/by/4.0/).

\section{Introduction}

One of the primary goals of medicinal chemistry is the development of new antimicrobial therapeutic agents. [1]. A review of the literature revealed that isatin possesses diverse chemotherapeutic activities such as antibacterial [2], antiviral [3], anti-HIV [4], antimycobacterial [5,6], anti-cancer [7,8], anti-inflammatory [9], and anticonvulsant [10,11]. The isatin nucleus is having anti-cancer drugs such as Sunitinib[12] (I, Figure 1), which is FDA approved drug for the treatment of cancers. Isatin was reported to be a potential target against Abl Tyrosine kinase [13], DNA topoisomerase [14], CDK2 Kinase [15]. Benzoxazoles have to found as antimicrobial [16,17], antihistaminic [18], anti-inflammatory [19], cytotoxic [20,21], antiparasitic[22] properties. Among all synthesized compounds, Tafamidis (2) (II, Figure 1) is a market-available drug used for the treatment of amelioration of transthyretin-related hereditary amyloidosis [23]. 
Among these properties, antimicrobial and antioxidant activities of this isatin moiety have been interestingly published by many researchers. Recently, the development of antimicrobial agents with cytotoxic properties has been a great success.

Considering the known factors of both isatin and benzoxazole moieties, we have designed and synthesized a library of benzoxazole-linked isatin (3a-j) and their structures characterized by NMR, and mass spectral data. Further, these compounds are tested for their antimicrobial and cytotoxic activity against four human cancer cell lines.
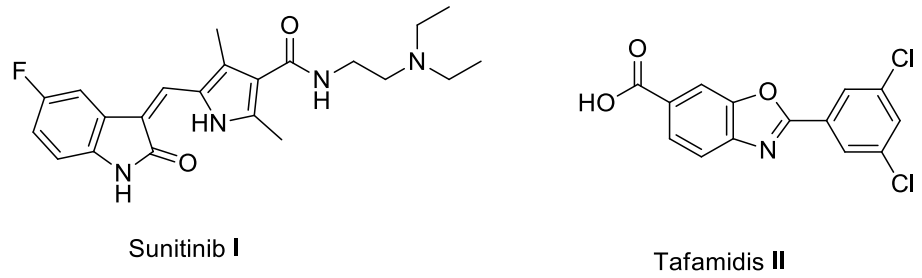

Figure 1. FDA-approved drugs Isatin and Benzoxazole scaffolds.

\section{Materials and Methods}

\subsection{General.}

Melting points (mp) have been determined using the Toshniwal device, expressed at ${ }^{\circ} \mathrm{C}$, and are not corrected. The IR spectra of the compounds were recorded on Thermo Nicolet Nexus 670S series, FT-IR spectrometer using KBr disc.1H NMR were recorded on an Avance$300 \mathrm{MHz}$ instrument using TMS as an internal standard(chemical shifts in $\delta$, ppm), mass spectra were recorded on an LC-MSD-Trap-SL. The completion of the reaction is checked on TLC. Further, the synthesized compounds were purified by column chromatography using Hexane, methanol solvents.

\subsection{Chemicals.}

All the solvents, reagents, and catalysts used are Analytical grade. All the chemicals and reagents for synthesis and biological activity were purchase from Himedia (Mumbai, India). 3-(4, 5-Dimethylthiazol-2-yl)-2, 5- diphenyltetrazolium bromide (MTT) was procured from Aldrich Sigma. Substituted isatins were prepared by the procedures reported in the literature.

\subsection{Chemistry. General procedures.}

\subsubsection{Synthesis of 2-aminobenzoxazole (2).}

2-amino phenol $(0.01 \mathrm{~mol})$ and Cyanogen bromide $(0.02 \mathrm{~mol})$ dissolved in toluene separately, and these two solutions were mixed slowly with a mechanical stirrer at $30^{\circ} \mathrm{C}$ for 6$8 \mathrm{hrs}$. The completion of the reaction is checked by TLC. The product is filtered and washed with $\mathrm{CCl}_{4}$, yield $68 \%$.mp. $116-120^{\circ} \mathrm{C}$

\subsubsection{Synthesis of Benzoxazole-Isatin conjugates (3).}

Equimolar 2-benzoxazol-2-amine(3) and 5 and 7- substituted isatin is dissolved in absolute alcohol in the presence of glacial acetic acid and was heated under reflux for 10-12 
hr. After completion of the reaction, it is allowed to cool at room temperature. The product was collected by filtration and dried and recrystallized by using different organic solvents.

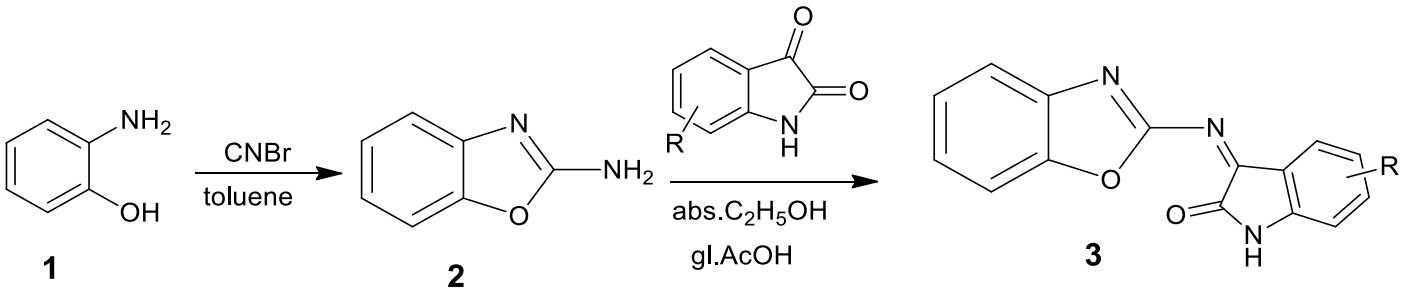

Scheme 1. Synthesis of some novel Benzoxazole-Isatin conjugates.

With IR, 1H NMR and mass spectral analytics, the chemical structures of the synthesized compounds were confirmed.

\subsection{Spectral data of synthesized compounds.}

3-(benzo[d]oxazol-2-ylimino)indolin-2-one (3a) $(\mathbf{R}=\mathbf{H})$ : IR $v\left(\mathrm{~cm}^{-1}\right): 3413(\mathrm{~N}-\mathrm{H}), 1724$ $(\mathrm{C}=\mathrm{O}), 1460(\mathrm{C}=\mathrm{N}), 1168(\mathrm{C}-\mathrm{O}-\mathrm{C})$; $1 \mathrm{H}$ NMR $\delta \mathrm{ppm}$ : 6.75-6.80 (m, 2H, Ar-H), 6.82-6.95 (m, 2H, Ar-H), 7.52-7.59 (m, 2H, Ar-H), 7.60-7.75 (m, 2H, Ar-H), 11.0 (s, 1H, indole NH); 13C NMR (DMSO-d6) $\delta$ ppm: 114.95, 118.63, 122.38, 122.67, 123.32, 123.59, 129.75, 130.30, 132.17, 138.69, 140.23, 154.76, 155.66, 162.67, 164.63; ESI: m/z value $264 ;$ m.p: $146-148^{\circ} \mathrm{C}$

3-(benzo[d]oxazol-2-ylimino)-5-fluoroindolin-2-one (3b) (R=5-F): IR v ( $\left.\mathrm{cm}^{-1}\right): 3214(\mathrm{~N}-$ $\mathrm{H}), 1719(\mathrm{C}=\mathrm{O}), 1405(\mathrm{C}=\mathrm{N}), 1287(\mathrm{C}-\mathrm{N}), 1194(\mathrm{C}-\mathrm{O}-\mathrm{C})$; $1 \mathrm{H}$ NMR $\delta$ ppm: 11.72 (s, 1H, indole $\mathrm{NH}), 7.78$ (s, 1H, Ar-H), 7.34-7.37 (d, 1H, Ar-H), 7.21-7.22 (d, 1H, Ar-H), 7.10-7.80 (m, 2H, Ar-H), 7.02-7.08 (m, 2H, Ar-H; ESI: m/z value 283; m.p: $134^{\circ} \mathrm{C}$

3-(benzo[d]oxazol-2-ylimino)-5-chloroindolin-2-one (3c) (R=Cl): IR v́ ( $\left.\mathrm{cm}^{-1}\right): 3211(\mathrm{~N}-$ $\mathrm{H}), 1702.26(\mathrm{C}=\mathrm{O}), 1584.44(\mathrm{C}=\mathrm{N}), 1304(\mathrm{C}-\mathrm{N}), 1161(\mathrm{C}-\mathrm{O}-\mathrm{C})$; $1 \mathrm{H}$ NMR $\delta$ ppm: $10.60(\mathrm{~s}, 1 \mathrm{H}$, indole NH), 8.27 (s, 1H, Ar-H), 7.26 (d, 1H, Ar-H), 7.59-7.39 (d, 1H, Ar-H), 7.75-7.50 (m, 2H, Ar-H), 7.82-7.70 (m, 2H, Ar-H),; ESI: m/z value 299; m.p: $188^{\circ} \mathrm{C}$

3-(benzo[d]oxazol-2-ylimino)-5-bromoindolin-2-one (3d) (R=Br): IR v́ ( $\left.\mathrm{cm}^{-1}\right): 3257(\mathrm{~N}-$ $\mathrm{H}), 1727(\mathrm{C}=\mathrm{O}), 1607(\mathrm{C}=\mathrm{N}), 1330(\mathrm{C}-\mathrm{N}), 1148(\mathrm{C}-\mathrm{O}-\mathrm{C})$; $1 \mathrm{H} \mathrm{NMR} \delta \mathrm{ppm}$ : $12.30(\mathrm{~s}, 1 \mathrm{H}$, indole $\mathrm{NH}), 7.50$ (s, 1H, Ar-H), 7.54-7.52 (d, 2H, Ar-H), 8.65-8.10 (m, 2H, Ar-H), 8.77-8.65 (m, 2H, Ar-H), ESI: m/z value 342; m.p: $320^{\circ} \mathrm{C}$

3-(benzo[d]oxazol-2-ylimino)-5-nitroindolin-2-one (3e) $\left(\mathbf{R}=\mathrm{NO}_{2}\right):$ IR v́ ( $\left.\mathrm{cm}^{-1}\right): 3285(\mathrm{~N}-$ $\mathrm{H}), 1710(\mathrm{C}=\mathrm{O}), 1570(\mathrm{C}=\mathrm{N}), 1350(\mathrm{C}-\mathrm{N}), 1159(\mathrm{C}-\mathrm{O}-\mathrm{C})$; $1 \mathrm{H}$ NMR $\delta$ ppm: 12.15 (s, 1H, indole $\mathrm{NH}), 8.12$ (s, 1H, Ar-H), 7.74-7.39 (d, 2H, Ar-H), 8.89-8.73 (m, 4H, Ar-H); ESI: m/z value 309; m.p: $214-216^{\circ} \mathrm{C}$

3-(benzo[d]oxazol-2-ylimino)-5-methylindolin-2-one (3f) $\left(\mathbf{R}=\mathbf{C H}_{3}\right)$ : IR $v\left(\mathrm{~cm}^{-1}\right): 3217(\mathrm{~N}-$ H), $2928(\mathrm{C}-\mathrm{H}), 1730(\mathrm{C}=\mathrm{O}), 1475(\mathrm{C}=\mathrm{N}), 1246(\mathrm{C}-\mathrm{N}), 1166(\mathrm{C}-\mathrm{O}-\mathrm{C}) ; 1 \mathrm{H}$ NMR $\delta$ ppm: 10.81 (s, 1H, indole NH), 7.95 (s, 1H, Ar-H), 7.42-7.44 (d, 2H, Ar-H), 6.65-7.11 (m, 4H, Ar-H), 2.23 (s, 3H, CH3); ESI: m/z value 278; m.p: $198{ }^{\circ} \mathrm{C}$

3-(benzo[d]oxazol-2-ylimino)-2-oxoindoline-5-carboxylic acid (3g) $(\mathbf{R}=\mathbf{C O O H})$ : IR v (cm $\left.{ }^{1}\right)$ : $3650(\mathrm{O}-\mathrm{H}), 3300(\mathrm{~N}-\mathrm{H}), 1770(\mathrm{C}=\mathrm{O}), 1485(\mathrm{C}=\mathrm{N}), \mathrm{O}-\mathrm{H}(1400), 1254(\mathrm{C}-\mathrm{N}), 1075(\mathrm{C}-\mathrm{OH})$; 1H NMR $\delta$ ppm: 12.50 (s, 1H, O-H), 12.02 (s, 1H, indole NH), 8.68 (s, 1H, Ar-H), 8.35-8.15 (d, 2H, Ar-H), 7.85-7.35 (m, 4H, Ar-H), ESI: m/z value 307; m.p: 242-244 ${ }^{\circ} \mathrm{C}$ 
methyl 3-(benzo[d]oxazol-2-ylimino)-2-oxoindoline-5-carboxylate (3h) $\left(\mathrm{R}=\mathbf{5}-\mathrm{COOCH}_{3}\right)$ : IR v $\left(\mathrm{cm}^{-1}\right)$ : $3285(\mathrm{~N}-\mathrm{H}), 3100(\mathrm{Ar}-\mathrm{H}), 2972(\mathrm{C}-\mathrm{H}), 1744(\mathrm{C}=\mathrm{O}), 1465(\mathrm{C}=\mathrm{N}), 1225(\mathrm{C}-\mathrm{N})$; $1 \mathrm{H}$ NMR $\delta$ ppm: 12.10 (s, 1H, indole NH), 8.54 (s, 1H, Ar-H), 8.28-8.12 (d, 2H, Ar-H), 7.65-7.46 (m, 4H, Ar-H), 3.95 (s, 3H, -CH3), ; ESI: m/z value 321; m.p: $238-240{ }^{\circ} \mathrm{C}$

3-(benzo[d]oxazol-2-ylimino)-7-chloroindolin-2-one (3i)(R=7-Cl): IR $v\left(\mathrm{~cm}^{-1}\right): 3375(\mathrm{~N}-$ H), $3125(\mathrm{Ar}-\mathrm{H}), 1752(\mathrm{C}=\mathrm{O}), 1482(\mathrm{C}=\mathrm{N}), 1245(\mathrm{C}-\mathrm{N}), 865(\mathrm{C}-\mathrm{Cl}) ; 1 \mathrm{H}$ NMR $\delta$ ppm: $12.65(\mathrm{~s}$, $1 \mathrm{H}$, indole NH), 8.24 (s, 1H, Ar-H), 8.10-7.85 (d, 2H, Ar-H), 7.62-7.40 (m, 4H, Ar-H),; ESI: m/z value 297 ; m.p: $300{ }^{\circ} \mathrm{C}$

3-(benzo[d]oxazol-2-ylimino)-7-bromoindolin-2-one (3j) (R=Br): IR v ( $\left.\mathrm{cm}^{-1}\right): 3382(\mathrm{~N}-$ H), $3132(\mathrm{Ar}-\mathrm{H}), 1758(\mathrm{C}=\mathrm{O}), 1445(\mathrm{C}=\mathrm{N}), 1250(\mathrm{C}-\mathrm{N}), 980(\mathrm{C}-\mathrm{Cl})$; $1 \mathrm{H}$ NMR $\delta$ ppm: 12.75 (s, $1 \mathrm{H}$, indole NH), 8.32 (s, 1H, Ar-H), 8.20-7.94 (d, 2H, Ar-H) 7.75-7.32 (m, 4H, Ar-H); ESI: $\mathrm{m} / \mathrm{z}$ value 341 ; m.p: $280-282{ }^{\circ} \mathrm{C}$

\subsection{In vitro antimicrobial activity.}

All the benzoxazole-isatin conjugates were screened for their in vitro antimicrobial activity by the broth micro-dilution procedures and principles of the CLSI[24]. Minimal inhibitory concentrations (MIC) for each compound were investigated against standard bacterial strains; E. coli and S.typhi (gram-negative); B. subtilis (gram-positive); C. albicans, and $A$. niger (fungal strain). Ciprofloxacin was used as a standard drug for antibacterial activity, while nystatin was used as a standard drug for antifungal activity.

\subsection{Evaluation of in vitro anti-cancer activity.}

MTT [3-(4, 5-Dimethylthiazol-2-yl)-2, 5- diphenyltetrazolium bromide] assay was used to evaluate the in vitro cytotoxicity of all the compounds against HeLa, MCF-7 and IMR32 human cancer cell lines[25].

\subsection{Molecular docking studies.}

The molecular docking studies were carried out using Samson software using Autodock Vina extension for all synthesized Benzoxazole-Isatin conjugates (3a-j). All the synthesized compounds were docked against Glucosamine-6-phosphate synthase (GlcN-6-P synthase) and telomerase.[26-28] The 3D structural proteins (PDB: 2VF5) were assessed from the protein data bank. The molecular docking studies of all Benzoxazole-Isatin conjugates (3a-j) in the active site of Glucosamine-6-phosphate synthase https://www.rcsb.org/structure/2VF5 were carried out to predict the binding efficiency. The synthesized compounds were also docked with Telomerase (PDB ID: 5CQG). The molecular docking scores are summarized in Table 2.

The protein structures were verified for missing residues and bond orders have checked and corrected, and terminal residues were adjusted and saved in .pdb format. All the ligand structures were drawn in Marvin's sketch and optimized into 3D structures. All the ligands were added explicit hydrogens and energy minimized at 1000 steps. The AutoDock Vina extension in Samson is used for docking the compounds against the molecular cancer targets. The receptor grid around their co-crystal ligands was generated. The number of docking poses is set as 10, exhaustiveness is set at 8 , and the number of best poses is given as 10 . The 3D and 2D interactions were generated with Discovery Studio. 


\subsection{In silico ADME Studies.}

The in silico ADME properties of Benzoxazole-Isatin conjugates (3a-j) were assessed by using Drug-likeness quantitative estimation (QED) with RDKit in Galaxy.[29] The following parameters were calculated Mol. Wt, ALOGP, Hydrogen Bond Acceptor (HBA), Hydrogen Bond Donor (HBD), Polar Surface Area (PSA), No of Rotatable Bonds (ROTB). The Lipinski rule was calculated. Toxicity parameters are calculated by using Data Warrior Software.[30]

\section{Results and Discussion}

\subsection{Chemistry.}

In the present study, 10 different novel benzoxazole-isatin conjugates (3a-j) were prepared by treating benzoxazol-2-amine with substituted isatin derivatives. The synthetic protocol was developed as depicted in Scheme 1. The physico-chemical properties of synthesized compounds were illustrated in Table 1 . The structures of all the compounds were elucidated by using FT-IR, 1H NMR, and mass spectral analysis. All the compounds gave satisfactory elemental analysis.

\subsection{In vitro antimicrobial activity.}

In the light, interesting antimicrobial activities of Benzoxazole-Isatin conjugates were screened for antibacterial and antifungal activity against Escherichia coli, Salmonella typhi, Bacillus subtilis, Candida albicans, and Aspergillus niger. The in vitro antimicrobial properties of all the synthesized compounds against Gram-ve and Gram+ve bacteria and yeasts are presented in Figure-2, respectively, and expressed in minimum inhibitory concentrations $(\mu \mathrm{g} / \mathrm{ml})$.

All the synthesized compounds significantly inhibited the growth of bacteria, and most of the MIC values were found between 10 and $100 \mu \mathrm{g} / \mathrm{ml}$, indicating their moderate antibacterial activity. Among all the compounds, compounds $3 \mathrm{~d}$ and $3 \mathrm{c}$ showing good antibacterial activity against tested gram-positive and negative bacteria (Figure 2). Compounds that showed MIC of $>100 \mu \mathrm{g} / \mathrm{ml}$ or above had not been included in the discussion.

The synthetic compounds significantly inhibited the growth of tested fungi (Figure 2), and the MIC values were found between $20 \& 100 \mu \mathrm{g} / \mathrm{ml}$.

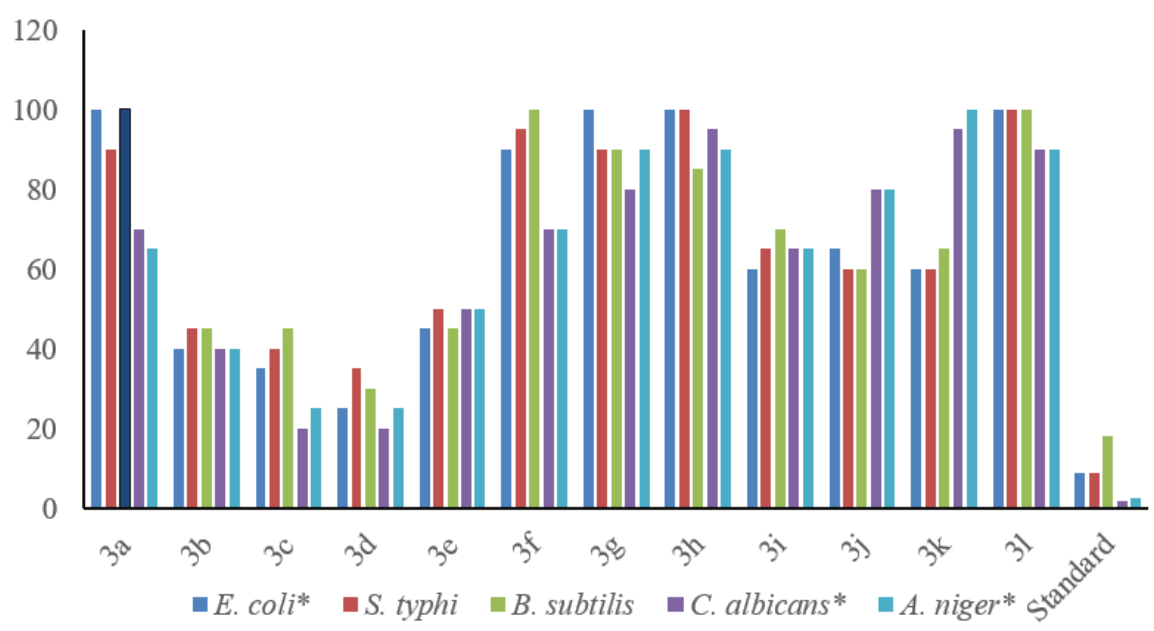

Figure 2. MIC values of $(\mu \mathrm{g} / \mathrm{ml})$ of synthesized compounds against tested bacteria. The minimum inhibitory concentration (MIC) of compounds was expressed as $\mu \mathrm{g} / \mathrm{ml}(\mathrm{n}=3)$. 
From the results of the antimicrobial activity of the synthesized benzoxazole-isatin conjugates, the following structure-activity relationships (SAR) can be derived:

i) It was observed that most of the 3-(benzoxazol-2-ylimino) indolin-2-one derivatives which are substituted with electron-withdrawing groups, showed better antimicrobial activity than those of non-substituted derivatives. These electron-withdrawing groups may decrease electron density on the benzene ring through the resonance effect.

ii) The antimicrobial activity of test compounds was more with compounds substituted with the electron-withdrawing group on $5^{\text {th }}$ position of isatin ring than $7^{\text {th }}$ position.

iii) Among all the potent antimicrobial agents, the high antimicrobial activity was shown by compounds $3 \mathrm{c}$ (5-Cl substituted) \& $3 \mathrm{~d}$ (5-Br substituted).

\subsection{In vitro anti-cancer activity.}

The anti-cancer activity of all the synthesized compounds (3a-j) was evaluated against HeLa, IMR-32 \& MCF-7 cancer cell lines using the MTT method and was almost equally active against the three cell types tested. The $\mathrm{IC}_{50}$ values of all the compounds were shown in Figure-3.

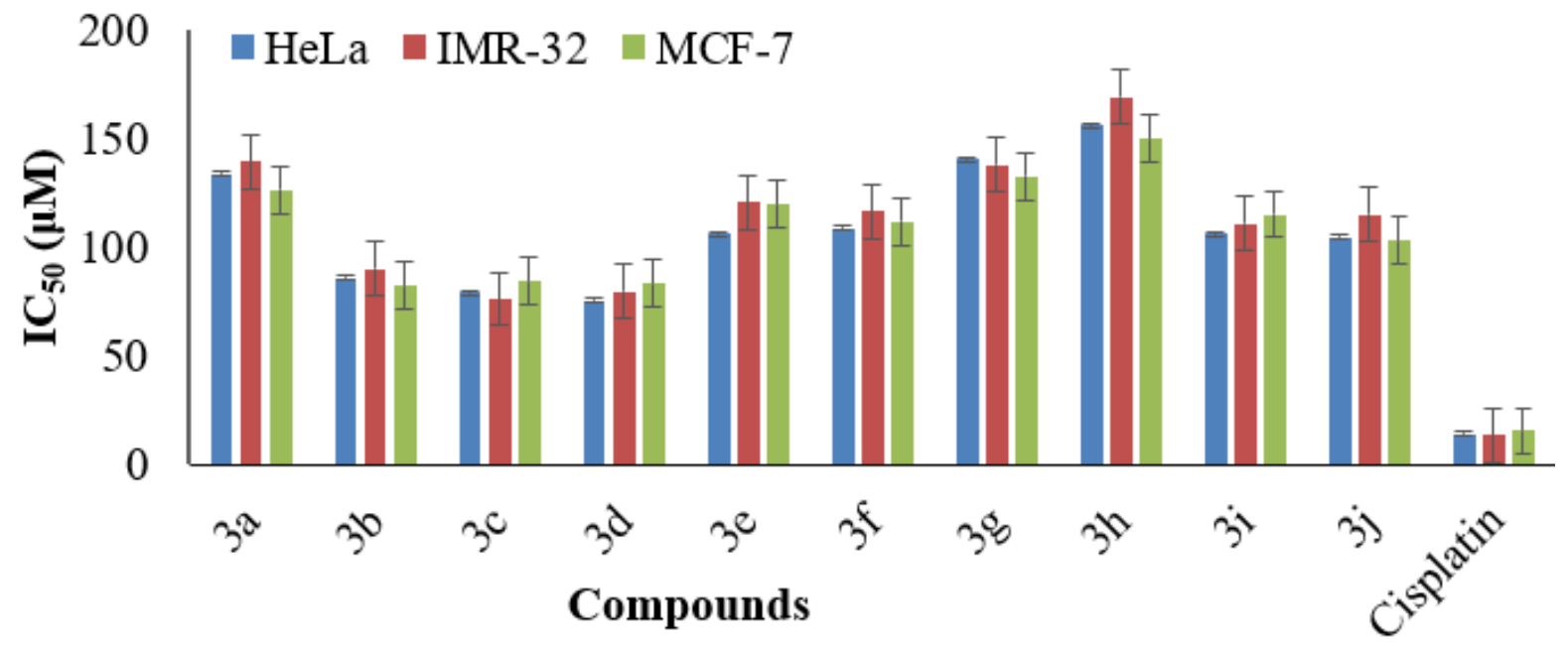

Figure 3. In-vitro cytotoxic activity of benzoxazole-isatin conjugates (3a-j) against HeLa, IMR-32 \& MCF-7 cancer cells using MTT assay.

The IC50 values of all the synthetic test compounds were found between 176.31 and $82.33 \mu \mathrm{M}$. Among all the test compounds, compound $3 \mathrm{~b}$ ( $\mathrm{R} 1$ substitution at $\mathrm{C} 5$ is $\mathrm{F} ; \mathrm{R} 2=\mathrm{H}$ ), 3d (R1 at C5-is Br; R2=H), 3c (R1 at C5-is Cl; R2=H), 3f (R1 at C5-is NO2; R2=H), and 3i ( $\mathrm{R} 2$ at $\mathrm{C} 5$-is $\mathrm{Cl} ; \mathrm{R} 1=\mathrm{H}$ ) having more potent cytotoxic activity against three cancer cell lines. Comparatively, among R1 substituted compounds, those substituted with electron-withdrawing groups (-F, $\mathrm{Cl}, \mathrm{Br}, \mathrm{NO}_{2}$, etc.) are found to be potent cytotoxic agents.

\subsection{Molecular docking studies with telomerase (PDB ID: 5CQG).}

The design and synthesized compounds were performed molecular docking studies with Telomerase (PDB ID: 5CQG). Telomerase is a ribonucleoprotein reverse transcriptase (RNP) which maintains genome integrity by replicating the ends of chromosomes. All the docked ligands have shown favorable interactions with the RNP and shown similar interactions with the co-crystal ligand. The binding energy with dock score values of all ligands with RNP are summarized in Table 2 and was found in the range from -7.56 to $-6.25 \mathrm{kcal} / \mathrm{mol}$. Among the ligands docked against telomerase, Compound $3 \mathrm{c}$ substituted with 5-chloro group on isatin 
has shown the highest docking score $-7.56 \mathrm{kcal} / \mathrm{mol}$ with $\mathrm{Ki}$ value of $3.15 \mu \mathrm{M}$. The oxygen atom of $\mathrm{C}=\mathrm{O}$ group of $3 \mathrm{c}$ exhibit $\mathrm{H}$-bond interaction with Asn192 with a bond distance of 1.47 $\mathrm{A}^{\mathrm{o}}$ and also forms $\mathrm{H}$-bond interactions with Asp254. It also forms electrostatic interactions with Asp254 residue. The hydrophobic interactions are formed with His304, Arg253, and Ala195 amino acid residues. (Figure-4) Compound 3d substituted with 5-bromo on isatin ring has exhibited the highest Vina dock Score $-7.97 \mathrm{kcal} / \mathrm{mol}$ with $\mathrm{Ki}$ value of $2.89 \mu \mathrm{M}$. The oxygen atom of $\mathrm{C}=\mathrm{O}$ group of $3 \mathrm{~d}$ exhibit $\mathrm{H}$-bond interaction with residues Ala195 with a bond distance of $2.04 \mathrm{~A}^{\circ}$ and Gln308 with bond distance $2.65 \mathrm{~A}^{\circ}$. It also forms hydrophobic interactions with amino acid residues of Arg194, Asp254 and Arg253 amino acid residues (Figure 5).

\subsection{Molecular docking studies with glucosamine-6-phosphate synthase (PDB ID: 2VF5).}

The synthesized compounds' design was performed by molecular docking studies with Glucosamine-6-phosphate synthase (PDB ID: 2VF5). All the docked ligands have shown favorable interactions with the GlcN-6-P synthase and shown similar interactions with the co-crystal ligand. The binding energy with dock score values of all ligands with GlcN-6-P synthase are summarized in Table-2 and was found in the range from -7.67 to $-6.24 \mathrm{kcal} / \mathrm{mol}$. Among the ligands docked against GlcN-6-P synthase, Compound 3c substituted with 5-chloro group on isatin has shown the highest docking score $-7.67 \mathrm{kcal} / \mathrm{mol}$ with $\mathrm{Ki}$ value of $1.78 \mu \mathrm{M}$. The nitrogen atom of benzoxazole group of $3 \mathrm{c}$ exhibit $\mathrm{H}$-bond interaction with Gln 475 residue with a bond distance of $2.17 \mathrm{~A}^{\mathrm{o}}$. It also forms pi interactions with Ala572, Ala520, and Asp474 amino acid residues. (Figure-6) Compound 3d substituted with 5-bromo on isatin ring has exhibited the highest Vina dock Score $-7.47 \mathrm{kcal} / \mathrm{mol}$ with $\mathrm{Ki}$ value of $1.89 \mu \mathrm{M}$. The nitrogen atom of isatin of $3 \mathrm{~d}$ exhibit $\mathrm{H}$-bond interaction with -NH2 group of Tyr576 residue with a bond distance of $2.27 \mathrm{~A}^{\circ}$. The ligand also forms electrostatic interaction with Asp548 residue and hydrophobic interactions with Phe553, Ala551, His566, Ala520 and Ala551 residues (Figure 7).

In summary, the designed compounds showed good anti-cancer activity and excellent free energy of binding interactions with Telomerase (PDB ID: 5CQG). The anti-cancer potential of the synthesized compound could have shown by inhibiting the molecular target such as telomerase. It is one of the most prominent targets in prostate cancer cells and predominantly maintains telomeres by activating telomerase. Assessment of telomere length and telomerase activity could be useful in the diagnosis and prognosis of cancer [3]. The synthesized compounds have shown prominent anti-cancer activity against the cancer cell lines viz., HeLa, IMR-32 \& MCF-7 and correlated with molecular docking studies against the protein target telomerase.

\subsection{In silico ADME and Toxicity prediction.}

The in silico ADME properties of Benzoxazole-Isatin conjugates (3a-j) were assessed by using Drug-likeness quantitative estimation (QED) with RDKit in Galaxy. All the compounds were determined molecular descriptors for Rule of 5 (Lipinski rule), which states the oral bioavailability and drug-like properties. The determinants are Molecular weight $\leq 500$, no of H-Acceptors $\leq 10$, no of H-Donor $\leq 5$. The molecules which violate more than one Ro5 will affect the bioavailability. Among the calculated chemical descriptors, all the ligands have passed the Lipinski rule, which states ligands which not violate more than one Ro5. (Table-2). 
All the synthesized compounds have shown good oral bioavailability, and none of the ligands have violated the Ro5. QED (Quantitative Estimation Drug-Likeliness) is calculated from eight properties such as M.W, ALOGP, HBA, HBD, PSA, ROTBs, AROMs, ALERTS. The value ranges from 0 (unfavorable properties) to 1 (favorable properties). The Druglikeness and Toxicity properties of all compounds are predicted by using Data Warrior Software. All the compounds have shown a positive value for drug-likeness, except $3 \mathrm{e}$ has shown a negative value. In silico toxicity prediction of all ligands was calculated by using Datawarrior software and shown free from the mutagenic, tumorigenic, irritant, and reproductive effectiveness.
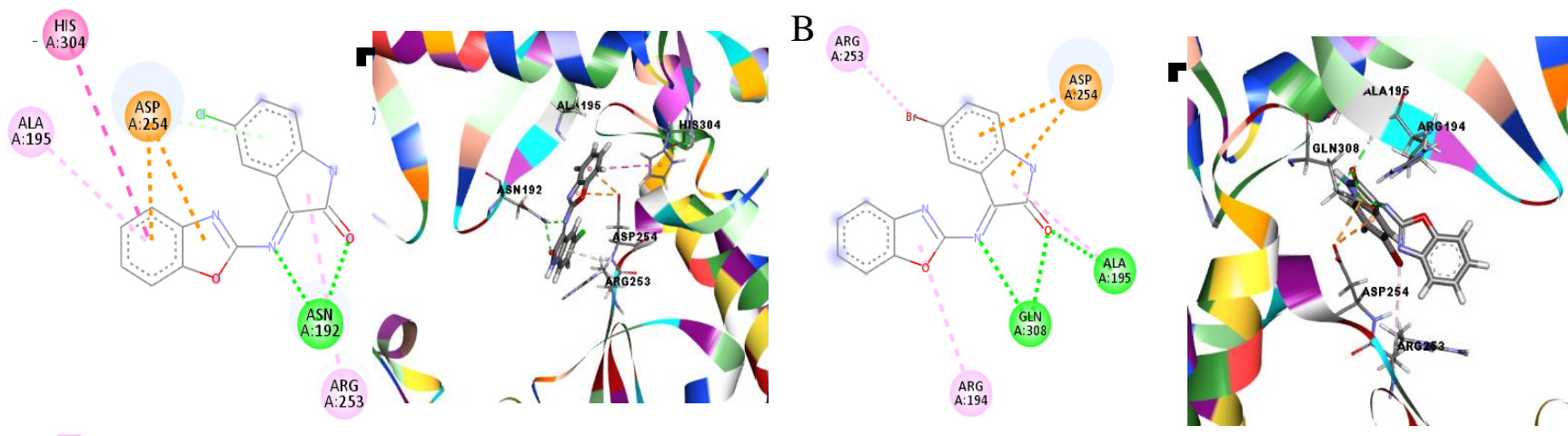

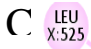
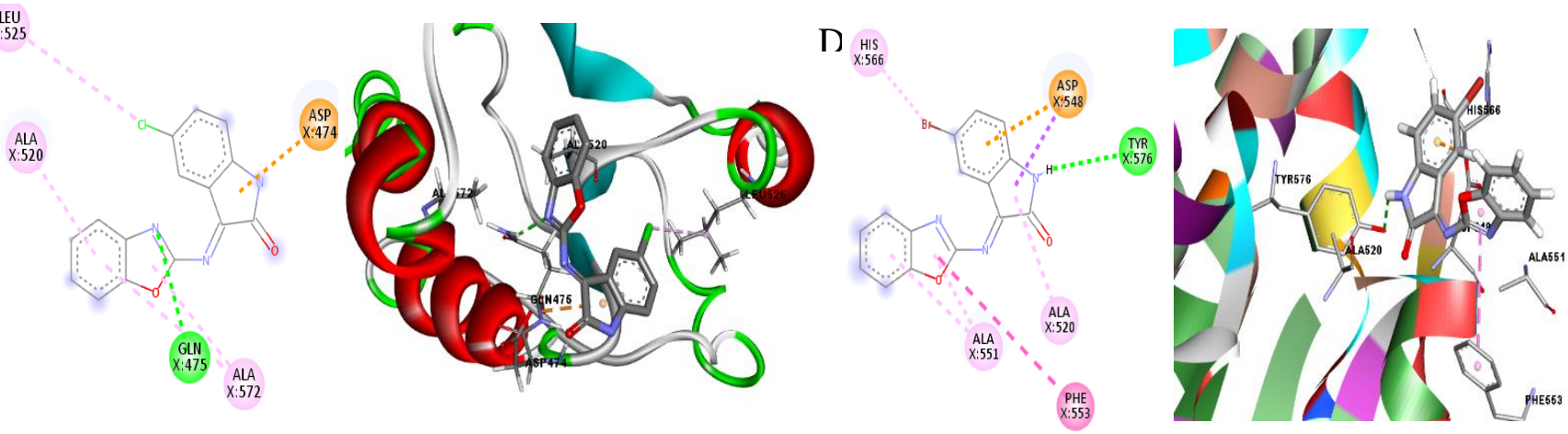

Figure 4. Molecular Docking 2D and 3D interactions (A) 3c with Telomerase (PDB ID: 5CQG); (B) 3d with Telomerase (PDB ID: 5CQG); (C) 3c with glucosamine-6-phosphate synthase (PDB ID: 2VF5); (D) 3d with glucosamine-6-phosphate synthase (PDB ID: 2VF5).

Table 1. Docking score and Binding interactions Benzoxazole-Isatin conjugates (3a-j) with Telomerase (PDB ID: 5CQG) and Glucosamine-6-phosphate Synthase (PDB ID: 2VF5).

\begin{tabular}{c|c|c|c|c|c}
\multirow{2}{*}{ S.No } & \multirow{2}{*}{ Compd } & \multicolumn{2}{|c|}{ Telomerase (5CQG) } & \multicolumn{2}{c}{$\begin{array}{c}\text { GlcN-6-P synthase } \\
(2 \mathbf{2 V 5})\end{array}$} \\
\cline { 3 - 6 } & & \multirow{2}{*}{ Binding Affinity } & \multirow{2}{*}{ Ki( $\boldsymbol{\mu M})$} & $\begin{array}{c}\text { Binding } \\
\text { Affinity }\end{array}$ & \multirow{2}{*}{ Ki $(\mu \mathbf{M})$} \\
\hline 1 & $3 \mathrm{a}$ & -7.25 & 3.52 & -7.12 & 2.27 \\
\hline 2 & $3 \mathrm{~b}$ & -7.12 & 3.92 & -7.28 & 2.92 \\
\hline 3 & $3 \mathrm{c}$ & -7.56 & 3.15 & -7.67 & 1.78 \\
\hline 4 & $3 \mathrm{~d}$ & -7.97 & 2.89 & -7.47 & 1.89 \\
\hline 5 & $3 \mathrm{e}$ & -7.38 & 3.10 & -7.25 & 2.01 \\
\hline 6 & $3 \mathrm{f}$ & -6.81 & 4.58 & -7.24 & 2.26 \\
\hline 7 & $3 \mathrm{~g}$ & -6.96 & 4.85 & -6.6 & 3.66 \\
\hline 8 & $3 \mathrm{~h}$ & -6.58 & 4.47 & -7.01 & 2.88 \\
\hline 9 & $3 \mathrm{i}$ & -6.71 & 4.02 & -6.58 & 2.74 \\
\hline 10 & $3 \mathrm{j}$ & -6.85 & 3.98 & -6.24 & 4.92
\end{tabular}


Table 2. Drug-likeness quantitative estimation (QED) with RDKit and Toxicity with Datawarrior Software Benzoxazole-Isatin conjugates (3a-j).

\begin{tabular}{|c|c|c|c|c|c|c|c|c|c|c|c|c|c|c|c|c|}
\hline Index & Compd & MW & ALOGP & HBA & HBD & PSA & ROTB & AROM & ALERTS & LRo5 & QED & $\begin{array}{c}\text { Drug } \\
\text { likeliness }\end{array}$ & Mutagenic & Tumorigenic & $\begin{array}{c}\text { Reproductive } \\
\text { Effective }\end{array}$ & Irritant \\
\hline 1 & $3 a$ & 281.25 & 3.04 & 3 & 1 & 67.49 & 1 & 3 & 0 & 0 & 0.76 & 1.70 & none & none & none & none \\
\hline 2 & $3 b$ & 263.26 & 2.90 & 3 & 1 & 67.49 & 1 & 3 & 0 & 0 & 0.75 & 3.04 & none & none & none & none \\
\hline 3 & $3 \mathrm{c}$ & 297.7 & 3.55 & 3 & 1 & 67.49 & 1 & 3 & 0 & 0 & 0.76 & 3.08 & none & none & none & none \\
\hline 4 & $3 d$ & 342.15 & 3.66 & 3 & 1 & 67.49 & 1 & 3 & 0 & 0 & 0.74 & 1.25 & none & none & none & none \\
\hline 5 & $3 e$ & 308.25 & 2.80 & 5 & 1 & 110.63 & 2 & 3 & 2 & 0 & 0.53 & -2.07 & none & none & none & none \\
\hline 6 & $3 f$ & 277.28 & 3.20 & 3 & 1 & 67.49 & 1 & 3 & 0 & 0 & 0.76 & 2.98 & none & none & none & none \\
\hline 7 & $3 g$ & 307.27 & 2.59 & 5 & 2 & 104.79 & 2 & 3 & 0 & 0 & 0.79 & 2.91 & none & none & none & none \\
\hline 8 & $3 \mathrm{~h}$ & 342.15 & 3.66 & 3 & 1 & 67.49 & 1 & 3 & 0 & 0 & 0.74 & 1.25 & none & none & none & none \\
\hline 9 & $3 \mathrm{i}$ & 297.7 & 3.55 & 3 & 1 & 67.49 & 1 & 3 & 0 & 0 & 0.76 & 3.08 & none & none & none & low \\
\hline 10 & $3 j$ & 321.29 & 2.68 & 5 & 1 & 93.79 & 2 & 3 & 1 & 0 & 0.74 & 0.67 & none & none & none & none \\
\hline
\end{tabular}

molecular weight (MW), octanol-water partition coefficient (ALOGP), number of hydrogen bond donors (HBDs), number of hydrogen bond acceptors (HBAs), molecular polar

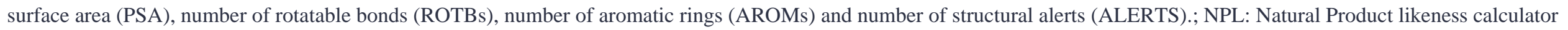




\section{Conclusions}

A new series of new benzoxazole-isatin conjugates were designed, synthesized, and were biologically evaluated for their in vitro antimicrobial and cytotoxic activities. The obtained compounds were isolated and purified using column chromatography and characterized by using FT-IR, NMR, and Mass Spectral data. The data of the biological activity have shown that the compounds substituted with halogens, i.e., electron-withdrawing groups $\left(-\mathrm{Cl},-\mathrm{Br},-\mathrm{NO}_{2}\right.$ group) substitution at $\mathrm{R} 1\left(5^{\text {th }}\right)$ position, are more active than the remaining tested compounds.

\section{Funding}

This research received no external funding.

\section{Acknowledgments}

The authors are thankful to Management and supporting staff of Vels Institute of Science, Technology and Advanced Studies (VISTAS), Pallavaram, Chennai, for providing the necessary facilities for carrying out the research.

\section{Conflicts of Interest}

The authors declare no conflict of interest.

\section{References}

1. Fernández de Ullivarri, M.; Arbulu, S.; Garcia-Gutierrez, E.; Cotter, P.D. Antifungal peptides as therapeutic agents. Frontiers in Cellular and Infection Microbiology 2020, 10, 105, https://doi.org/10.3389/fcimb.2020.00105.

2. Hassan, M.; Ghaffari, R.; Sardari, S.; Farahani, Y.F.; Mohebbi, S. Discovery of novel isatin-based thiosemicarbazones: synthesis, antibacterial, antifungal, and anti-mycobacterial screening. Research in Pharmaceutical Sciences 2020, 15, 281, https://doi.org/.10.4103/1735-5362.288435.

3.S evinçli, Z.Ş.; Duran, G.N.; Özbil, M.; Karal, N. Synthesis, molecular modeling and antiviral activity of novel 5-fluoro-1H-indole-2, 3-dione 3-thiosemicarbazones. Bioorganic Chemistry 2020, 104, 104202, https://doi.org/10.1016/j.bioorg.2020.104202.

4. Chauhan, G.; Pathak, D.P.; Ali, F.; Bhutani, R.; Kapoor, G.; Khasimbi, S. Advances in Synthesis, Derivatization and Bioactivity of Isatin: A Review. Current Organic Synthesis 2021, 18, 37-74, https://doi.org/10.2174/1570179417666200924150907.

5. Elsayed, Z.M.; Eldehna, W.M.; Abdel-Aziz, M.M.; El Hassab, M.A.; Elkaeed, E.B.; Al-Warhi, T.; AbdelAziz, H.A.; Abou-Seri, S.M.; Mohammed, E.R. Development of novel isatin-nicotinohydrazide hybrids with potent activity against susceptible/resistant Mycobacterium tuberculosis and bronchitis causing-bacteria. Journal of Enzyme Inhibition and Medicinal Chemistry 2021, 36, 384-393, https://doi.org/10.1080/14756366.2020.1868450.

6. Kumar, R.; Takkar, P. Repositioning of Isatin hybrids as novel anti-tubercular agents overcoming pre-existing antibiotics resistance. Medicinal Chemistry Research 2021, 1-30, https://link.springer.com/article/10.1007/s00044-021-02699-5.

7. Sevinçli, Z.Ş.; Cantürk, Z.; Dikmen, M.; KARALI, N. Anticancer and antituberculosis effects of 5-fluoro1H-indole-2, 3-dione 3-thiosemicarbazones. Istanbul Journal of Pharmacy 2020, 50, 176-180, https://dergipark.org.tr/en/pub/iujp/issue/42667/850022.

8. Haribabu, J.; Alajrawy, O.I.; Jeyalakshmi, K.; Balachandran, C.; Krishnan, D.A.; Bhuvanesh, N.; Aoki, S.; Natarajan, K.; Karvembu, R. N-substitution in isatin thiosemicarbazones decides nuclearity of $\mathrm{Cu}$ (II) complexes-Spectroscopic, molecular docking and cytotoxic studies. Spectrochimica Acta Part A: Molecular and Biomolecular Spectroscopy 2021, 246, 118963, https://doi.org/10.1016/j.saa.2020.118963. 
9. Joshi, D. To synthesize, characterization and pharmacological evaluation of novel substituted Isatin derivatives. J. Biomed. Pharm. Res 2020, 9, 51-60, https://doi.org/10.32553/jbpr.v9i1.719.

10. Osman, H.M.; Elsaman, T.; Yousef, B.A.; Elhadi, E.; Ahmed, A.A.; Eltayib, E.M.; Mohamed, M.S.; Mohamed, M.A. Schiff Bases of Isatin and Adamantane-1-Carbohydrazide: Synthesis, Characterization and Anticonvulsant Activity. Journal of Chemistry 2021, 2021, https://doi.org/10.1155/2021/6659156.

11. Deswal, S.; Tittal, R.K.; Vikas, D.G.; Lal, K.; Kumar, A. 5-Fluoro-1H-indole-2, 3-dione-triazoles-synthesis, biological activity, molecular docking, and DFT study. Journal of Molecular Structure 2020, 1209, 127982 , https://doi.org/10.1016/j.molstruc.2020.127982.

12. Mihçıokur, Ö.; Özpozan, T. Molecular structure, vibrational spectroscopic analysis (IR \& Raman), HOMOLUMO and NBO analysis of anti-cancer drug sunitinib using DFT method. Journal of Molecular Structure 2017, 1149, 27-41, https://doi.org/10.1016/j.molstruc.2017.07.064.

13. Al-Salem, H.S.; Arifuzzaman, M.; Issa, I.S.; Rahman, A. Isatin-Hydrazones with Multiple Receptor Tyrosine Kinases (RTKs) Inhibitory Activity and In-Silico Binding Mechanism. Applied Sciences 2021, 11, 3746, https://doi.org/10.3390/app11093746.

14. Eldehna, W.M.; El Hassab, M.A.; Abo-Ashour, M.F.; Al-Warhi, T.; Elaasser, M.M.; Safwat, N.A.; Suliman, H.; Ahmed, M.F.; Al-Rashood, S.T.; Abdel-Aziz, H.A. Development of isatin-thiazolo [3, 2-a] benzimidazole hybrids as novel CDK2 inhibitors with potent in vitro apoptotic anti-proliferative activity: Synthesis, biological and molecular dynamics investigations. Bioorganic Chemistry 2021, 110, 104748, https://doi.org/10.1016/j.bioorg.2021.104748.

15. Al-Salem, H.S.; Arifuzzaman, M.; Alkahtani, H.M.; Abdalla, A.N.; Issa, I.S.; Alqathama, A.; Albalawi, F.S.; Rahman, A. A Series of Isatin-Hydrazones with Cytotoxic Activity and CDK2 Kinase Inhibitory Activity: A Potential Type II ATP Competitive Inhibitor. Molecules 2020, 25, 4400, https://doi.org/10.3390/molecules25194400.

16. Erol, M.; Celik, I.; Temiz-Arpaci, O.; Kaynak-Onurdag, F.; Okten, S. Design, synthesis, molecular docking, density functional theory and antimicrobial studies of some novel benzoxazole derivatives as structural bioisosteres of nucleotides. Journal of Biomolecular Structure and Dynamics 2020, 1-12, https://doi.org/10.1080/07391102.2020.1760134.

17. Kashid, B.B.; Ghanwat, A.A.; Khedkar, V.M.; Dongare, B.B.; Shaikh, M.H.; Deshpande, P.P.; Wakchaure, Y.B. Design, Synthesis, In Vitro Antimicrobial, Antioxidant Evaluation, and Molecular Docking Study of Novel Benzimidazole and Benzoxazole Derivatives. Journal of Heterocyclic Chemistry 2019, 56, 895-908, https://doi.org/10.1002/jhet.3467.

18. Abdelgawad, M.A.; Bakr, R.B.; Ahmad, W.; Al-Sanea, M.M.; Elshemy, H.A. New pyrimidinebenzoxazole/benzimidazole hybrids: Synthesis, antioxidant, cytotoxic activity, in vitro cyclooxygenase and phospholipase A2-V inhibition. Bioorganic chemistry 2019, 92, 103218, https://doi.org/10.1016/j.bioorg.2019.103218.

19. Obafemi, C.A.; Adegbite, O.B.; Fadare, O.A.; Iwalewa, E.O.; Omisore, N.O.; Sanusi, K.; Yilmaz, Y.; Ceylan, Ü. Tryptanthrin from microwave-assisted reduction of isatin using solid-state-supported sodium borohydride: DFT calculations, molecular docking and evaluation of its analgesic and anti-inflammatory activity. Heliyon 2021, 7, e05756, https://doi.org/10.1016/j.heliyon.2020.e05756.

20. Padmini, T.; Vagdevi, H.; Jinendra, U.; Ravikiran, B. Synthesis of benzoxazole derivatives by Mannich reaction and invitro cytotoxic, antimicrobial and docking studies. Chemical Data Collections 2021, 31, 100628, https://doi.org/10.1016/j.cdc.2020.100628.

21. Osmaniye, D.; Çelikateş, B.K.; Sağlık, B.N.; Levent, S.; Çevik, U.A.; Çavuşoğlu, B.K.; Ilgın, S.; Özkay, Y.; Kaplancikl1, Z.A. Synthesis of some new benzoxazole derivatives and investigation of their anticancer activities. European Journal of Medicinal Chemistry 2021, 210, 112979, https://doi.org/10.1016/j.ejmech.2020.112979.

22. Philip Raja, S.; Jayamoorthy, K.; Dhanalekshmi, K.; Suresh, S. Mn3O4 nanoparticles bearing 5-amino-2mercapto benzimidazole moiety as antibacterial and antifungal agents. Journal of Biomolecular Structure and Dynamics 2021, 1-7, https://doi.org/10.1080/07391102.2021.1894237.

23. Rozenbaum, M.H.; Garcia, A.; Grima, D.; Tran, D.; Bhambri, R.; Stewart, M.; Li, B.; Heeg, B.; Postma, M.; Masri, A. Health Impact of Tafamidis in Transthyretin Amyloid Cardiomyopathy patients: An Analysis from the Tafamidis in Transthyretin Cardiomyopathy Clinical Trial (ATTR-ACT) and the Open-Label Long-term Extension Studies. European Heart Journal-Quality of Care and Clinical Outcomes 2021, https://doi.org/10.1093/ehjqcco/qcab031. 
24. Morishige, H.; Mano, Y.; Oguri, T.; Furuya, N. Comparison of four reading methods of broth microdilution based on the Clinical and Laboratory Standards Institute M27-A3 method for Candida spp. Japanese Journal of Antibiotics 2012, 65, 335, https://pubmed.ncbi.nlm.nih.gov/23383435/.

25. Abe, K.; Matsuki, N. Measurement of cellular 3-(4, 5-dimethylthiazol-2-yl)-2, 5-diphenyltetrazolium bromide (MTT) reduction activity and lactate dehydrogenase release using MTT. Neuroscience research 2000, 38, 325-329, https://doi.org/10.1016/S0168-0102(00)00188-7.

26. Wojciechowski, M.; Milewski, S.; Mazerski, J.; Borowski, E. Glucosamine-6-phosphate synthase, a novel target for antifungal agents. Molecular modelling studies in drug design. Acta Biochimica Polonica 2005, 52, 647-653, https://doi.org/10.18388/abp.2005_3425.

27. Baginski, M.; Serbakowska, K. In silico design of telomerase inhibitors. Drug discovery today 2020, 25 , 1213-1222, https://doi.org/10.1016/j.drudis.2020.04.024.

28. Mohsen, G.; A.M. Abdula; Jassim, A.; Rodhan, W.; Ayrim, N. New 3, 5-disubstituted-4, 5-dihydroisoxazole derivatives: Synthesis, antimicrobial, antioxidant and docking study against glucosamine-6-phosphate synthase. In Proceedings of the Journal of Physics: Conference Series 2021, p. 012042, https://iopscience.iop.org/article/10.1088/1742-6596/1853/1/012042.

29. Jia, C.-Y.; Li, J.-Y.; Hao, G.-F.; Yang, G.-F. A drug-likeness toolbox facilitates ADMET study in drug discovery. Drug Discovery Today 2020, 25, 248-258, https://doi.org/10.1016/j.drudis.2019.10.014.

30. Sander, T.; Freyss, J.; von Korff, M.; Rufener, C. DataWarrior: an open-source program for chemistry aware data visualization and analysis. Journal of chemical information and modeling 2015, 55, 460-473, https://doi.org/10.1021/ci500588j. 